\title{
Making Sense of Situations and Language Choices in Mathematical Word Problem Solving: A Case of Grade 9 Second Language Learners
}

\author{
Percy Sepeng \\ University of South Africa \\ E-mail: sepenp@unisa.ac.za
}

Doi:10.5901/ajis.2013.v2n3p165

\begin{abstract}
The issues of second language learning and meaning-making within multiple contexts were investigated in the study reported in this article. The study followed a mixed method design with quantitative data informing the qualitative results with a sample of 176 grade 9 students in six township schools of South Africa. Analysis of the data generated from a test appeared to suggest that the language of both a learner and that is used in a mathematical word problem tasks impacted on the way the tasks were interpreted. Furthermore, the study demonstrated that the learners' problem-solving skills in English (language used for teaching and learning) are by far adequate compared to isiXhosa (Learners' home language) during problem-solving. However, learners abilities to consider reality when solving real wor(I)d problems appeared to be marginally better in isiXhosa compared to English. Analysis of learners' interviews illustrates that, although English is the preferred Language of Learning and Teaching, they proposed a dual-use and/or parallel-use of English and isiXhosa for teaching and learning mathematics. Moreover, the findings seemed to suggest that learners appeared to be successful problem-solvers in cases where the dualuse of Language of Learning and Teaching, and learners' home language was evident during word problem solving processes.
\end{abstract}

Keywords: language; problem-solving; meaning-making; word problems

\section{Introduction}

The issues of language use, making sense of mathematical problem statement and a notion of considering the use of contexts in the teaching and learning of mathematics forms important part of South African school mathematics curricula. It is also acknowledged that education policies and language-in-education policies (LiEPs) are determined by economic interests and political ideologies (Taylor \& Vinjevold, 1999). This is usually common in remote parts of South African schools characterised by lack resources and qualified teachers of mathematics. The LiEP in South Africa implies that mathematics teachers and learners have to negotiate, agree, and decide which language to use, how and when to use it, in the teaching and learning of mathematics in multilingual classrooms. As a consequence, the choice of language use becomes dependent on issues of power and access. Moreover, in previously marginalised schools of South Africa, mathematics teachers may prefer to use English, which is the language that is most probably not spoken at home, but which they believe provides learners access to power, social goods and prepares them for tertiary education (Setati, 2005a). Despite a continuing debate in South African education regarding language use for teaching and learning in multilingual classrooms (e.g., Güles, 2005; Howie, 2003, 2004), learners continue to struggle with comprehending mathematical tasks that are embedded within the language of teaching and learning which results in poor mathematics achievements amongst second language learners (Sepeng, 2013). This debate centres on the language that should be used for teaching, learning, and assessment. In South Africa, an overwhelming majority of township and rural schools officially use English as a language of teaching and learning and for assessment purposes, despite the fact that the learners in these schools often have little contact with and access to English (Taylor \& Vinjevold, 1999).

\section{Literature Review}

In this section I present issues that relate mathematics achievements and language use in the teaching and learning of school mathematics; factors that appeared to affect second language learners are discussed within the contexts of reading in the official language of learning and teaching as well as reading comprehension strategies during word problem solving; the section is concluded by looking at notion of meanining-making in word problem solving. 


\subsection{Reading comprehension of English second language speakers}

In South African multilingual primary school classrooms, learners' achievement in reading comprehension strategies becomes a necessity when learners interpret word problems, and the efficacy of instruction in reading comprehension strategies is widely documented (De La Paz \& Graham, 1997; Loranger, 1997). Padron (1985) taught English second language reading comprehension strategies, and this improved learners' reading comprehension. Jonassen (2004) points out that story problem-solving requires not only calculation accuracy but also the comprehension of textual information, the capacity to visualise the data, the capacity to recognise the semantic structure of the problem, the capacity to sequence their solution activities correctly, and the capacity and willingness to evaluate the process that they use to solve the problem.

Studies on second language reading (e.g. Phillips, 1984; Sutton, 1989) report that effective reading can be taught and thus may help learners become better readers. In their study, Cummins, Kintsch, Reusser and Weimer (1988) found that much of the difficulty children experience with word problems can be attributed to difficulty in comprehending abstract or ambiguous language. They point out that structural recall, both correct and erroneous, provides clear evidence that children's problem-solving strategies are determined by their comprehension of the problem stories. Moreover, frequently observed conceptual errors were related to story miscomprehension in systematic ways. Cummins et al. (1988) assume that when a child recalls a problem, he or she describes the problem representation he or she constructed during a solution attempt.

\subsection{Meaning making in word problem solving}

The newly introduced South African Curriculum Assessment and Policy Statement emphasises not only in the teaching of problem-solving, but pleads for (more) instructional attention to the acquisition of problem-posing skills (Department of Basic Education, 2012). In developed countries, such as the US, there is also a growing interest among researchers in problem-posing (see e.g., English, 1998; Kilpatrick, 1987; Verschaffel, Van Dooren, Chen \& Stessen, 2009). According to Verschaffel and his colleagues (2009), the most cited motivation for instructional and curricular interest in problem-posing is its perceived potential value in assisting students to become better problem solvers. To explore this potential value, several studies (Cai \& Hwang, 2002; Ellerton, 1986; Silver \& Cai, 1996) have been set up to investigate the relationship between word problems solving and word problem-posing. In these studies, students were given opportunities to generate a few problems starting from a situational description, a cartoon (or picture), and afterwards, the quality of the mathematical problems produced by the students was compared with their ability to solve problems.

In their recent international comparative study, Cai and Hwang (2002) worked with a sample of grade six students from China and the US respectively and administered three pairs of problem-solving and problem-posing tasks. Each pair of problem-solving and problem-posing tasks involved one mathematical situation (e.g., the first three figures of an increasing square dot pattern consisting of 9, 16, 25 dots respectively). The problem-solving task for this situation included three word problems built around this situation, whereas the problem-posing task required students to generate one easy, one moderately difficult, and one difficult problem starting from the same situation. Their results revealed a close relationship between word problem-solving and word problem-posing. The close relationship was more evident among Chinese students because the variety of problems posed was clearly associated with their problem-solving success; furthermore, the difficulty of the self-generated problems was positively associated with the use of abstract problem-solving strategies. For the American students, the relationship between problem-posing variety and type, and problem-solving success was much weaker. Chai and Hwang (2002) point out that the stronger link between problemsolving and problem-posing for Chinese students might be attributed to the fact that the American students used less abstract problem-solving strategies.

\section{Research Methodology}

The study reported in the current article used both quantitative and qualitative methods following an administering of a test that was prepared in both English (official language of learning and teaching [LoLT] in participating schools) and isiXhosa (language used by learners at home). The study can be viewed as a mixed method design with quantitative data informing the qualitative results (Babbie \& Mouton, 2008). 


\subsection{Design type}

Quantitative data were collected from a test comprised of 3 mathematical word problem tasks that assisted in exploring learners' sense-making and problem-solving abilities. Four township secondary schools were chosen as a convenience sample of a cluster of similar schools in a district. The sample consisted of four ninth grade learners [n=176]. Half of the learners wrote the test in isiXhosa test first and then immediately repeated the test in English; the other half wrote the same test in English and then in isiXhosa. The test assisted me to establish how the learners use language (and the problems they experience) to solve mathematics problems in isiXhosa (learners' home language) and English (LoLT) and what problems they may have mathematically. A sample of grade nine learners (focus group) was interviewed after the test (the questions asked were informed by the results of the test) to find out where they had problems and why they solved the word problems the way they did.

\subsection{Materials}

Learners responses (or answers) to the three problem solving (PS) tasks were coded into three general categories: realistic reaction (RR), no reaction (NR), other reaction (OR), which were adapted from a schema developed by Verschaffel, De Corte, \& Lasure (1994). The RR comprised all cases wherein a learner either gave the most accurate numerical response that also considered real-world aspects and context of the problem, or cases where there was an attempt to consider real-world situations without providing a numerically most correct response. On the other hand, OR were all those responses without real-world considerations, and situationally inaccurate responses with correct computations. NR were all the cases with no numerical responses and mathematically incorrect, without any further written responses that indicated that the learner was not aware of real-life aspects of the problem that made it impossible for him or her to solve the problem. The following word problems (in a test) were administered to the learners and presented in both English (official LoLT) and isiXhosa (learners' home language):

Table 1. Problem Solving task 1 (PS1)

\begin{tabular}{|c|c|}
\hline $\begin{array}{l}\text { PS1: } 100 \text { children are being transported by minibuses to a } \\
\text { summer camp at the sea-side. Each minibus can hold a } \\
\text { maximum of } 8 \text { children. How many minibuses are needed? }\end{array}$ & $\begin{array}{l}\text { Abantwana abali-100 bahamba ngebhasi encinane besiya konwaba } \\
\text { ngaselwandle. Ibhasi nganye ithwala abantwana abasi }-8 \text {. } \\
\text { Kufuneka iibhasi ezingaphi zokubathwala bonke? }\end{array}$ \\
\hline $\begin{array}{l}\text { PS2: Two boys, Sibusiso and Vukile, are going to help } \\
\text { Sonwabo rake leaves on his plot of land. The plot is } 1200 \\
\text { square meters. Sibusiso rakes } 700 \text { square meters during } \\
\text { four hours and Vukile does } 500 \text { square meters during two } \\
\text { hours. They get } 180 \text { rands (R) for their work. How are the } \\
\text { boys going to divide the money so that it is fair? }\end{array}$ & $\begin{array}{l}\text { Amakhwenkwe amabini, uSibusiso noVukile baya kuncedisa } \\
\text { uSonwabo arhugule amagqabi entsimini yakhe. Ubukhulu bentsimi } \\
\text { yakhe yi }-1200 \text { yee skwe mitha. Ngeeyure ezi-4, uSibusiso } \\
\text { urhugule indawo ebukhulu bungama- } 700 \text { ee skwe mitha, waza } \\
\text { uVukile yena warhugula }-500 \text { skwe mitha ngeeyure ezimbini. } \\
\text { Bebobabini bafumana imali eyi R180 ngalo msebenzi. Baza } \\
\text { kwahlulelana kanjani ngale mali ukuze bangaqhathani? }\end{array}$ \\
\hline $\begin{array}{l}\text { PS3: John's best time to run } 100 \text { meters is } 17 \text { seconds. How } \\
\text { long will it take him to run } 1 \text { kilometre? }\end{array}$ & $\begin{array}{l}\text { UJohn ubaleka umgama ongama - } 100 \text { eemitha ngemizuzwana eli- } \\
\text { 17. Uya kuthatha ixesha elingakanani ukubaleka ikhilomitha enye? }\end{array}$ \\
\hline
\end{tabular}

\section{Quantitative Results}

The analysis done on PS tasks focused on computational (or mathematical) correctness of learners' solutions, together with situational accurateness (or appropriateness) of their responses. This section of the article discussed both quantitative data gathered via administering a test, and towards the end, qualitative info is presented.

\subsection{The effect of language (home or LoLT) use in word problem-solving}

Table 2 depicts data generated from learners' tests on the problem-solving (PS) tasks in both English and isiXhosa items. The overall percentages of RRs in the isiXhosa and English test respectively were $15 \%$ and $12 \%$, which indicate that learners' responses were more mathematically correct and situationally accurate in the isiXhosa test than the English test. As such, a more detailed look at the responses revealed that these realistic reactions (RRs) in the isiXhosa test produced more computationally correct other reactions (ORs) for PS1 and PS3, respectively, 37\%, and 55\%. 
Table 2. Percentages (and absolute numbers) of realistic reactions (RRs), other reactions (ORs), and no reactions (NRs) on the three problem-solving (PS) English and isiXhosa items for the Experimental group

\begin{tabular}{ccccccccc}
\hline Item & PS1 & PS2 & PS3 & Total & PS1 & PS2 & PS3 & Total \\
\hline & \multicolumn{3}{c}{ English Items } & & \multicolumn{5}{c}{ isiXhosa Items } \\
\cline { 2 - 9 } RR & $27 \%$ & $5 \%$ & $4 \%$ & $12 \%$ & $10 \%$ & $29 \%$ & $6 \%$ & $15 \%$ \\
& $(29)$ & $(5)$ & $(4)$ & $(38)$ & $(11)$ & $(31)$ & $(6)$ & $(48)$ \\
OR & $34 \%$ & $42 \%$ & $23 \%$ & $33 \%$ & $37 \%$ & $39 \%$ & $55 \%$ & $44 \%$ \\
& $(36)$ & $(45)$ & $(25)$ & $(106)$ & $(39)$ & $(42)$ & $(59)$ & $(140)$ \\
NR & $39 \%$ & $53 \%$ & $73 \%$ & $55 \%$ & $53 \%$ & $32 \%$ & $39 \%$ & $40 \%$ \\
& $(42)$ & $(57)$ & $(78)$ & $(38)$ & $(57)$ & $(34)$ & $(42)$ & $(48)$ \\
\hline
\end{tabular}

Overall, the percentages of ORs on the three PS tasks for the isiXhosa and the English items were 44\% and 33\%, respectively. In other words, the overall quantitative results suggest that more mathematically correct responses were produced in the isiXhosa test of the test compared to the English tests, but these solutions were situationally inaccurate. PS3 item produced a high percentage (73\%) of no reactions (NRs) than other PS tasks in both items, which suggested learners' lack of awareness to succeed in realistic modelling of word problems.

\subsection{The effect of test order on the problem solving and sense-making}

The results of Table 3, which show the percentage of the isiXhosa-English (IE) group learners who wrote the isiXhosa test first, indicate that seeing the paper in learners' home language had no effect on achievement scores of the English test. However, $41 \%$ of the mathematically correct responses were obtained in the isiXhosa test, with $60 \%$ of these responses generated on PS3 item compared to almost a third of the ORs produced on the same item of the English test. So the percentage of RRs in PS2 (of the isiXhosa test) was somewhat more than that in PS1 and PS3, whereas the reverse was true for the other answers (ORs). The finding that PS2 yielded more RRs than PS1 is consistent with most previous studies showing lower percentages of realistic answers in a problem with division with a remainder (e.g., Verschaffel, Greer, \& De Corte, 2000, Verschaffel et al., 2009). This finding was not the case with responses in the English test for the IE group.

Table 3. Percentages (and absolute numbers) of realistic reactions (RRs), other reactions (ORs), and no reactions (NRs) on the three problem-solving (PS) items for the isiXhosa-English (IE) Experimental group

\begin{tabular}{ccccccccc}
\hline Item & PS1 & PS2 & PS3 & Total & PS1 & PS2 & PS3 & Total \\
\hline & \multicolumn{3}{c}{ isiXhosa Items } & & \multicolumn{4}{c}{ English Items } \\
\cline { 2 - 9 } RR & $13 \%$ & $36 \%$ & $5 \%$ & $18 \%$ & $35 \%$ & $7 \%$ & $5 \%$ & $16 \%$ \\
& $(7)$ & $(20)$ & $(3)$ & $(30)$ & $(19)$ & $(4)$ & $(3)$ & $(26)$ \\
OR & $33 \%$ & $31 \%$ & $60 \%$ & $41 \%$ & $30 \%$ & $49 \%$ & $25 \%$ & $35 \%$ \\
& $(18)$ & $(17)$ & $(33)$ & $(68)$ & $(17)$ & $(27)$ & $(14)$ & $(58)$ \\
NR & $55 \%$ & $33 \%$ & $35 \%$ & $41 \%$ & $35 \%$ & $44 \%$ & $69 \%$ & $49 \%$ \\
& $(30)$ & $(18)$ & $(19)$ & $(67)$ & $(19)$ & $(24)$ & $(38)$ & $(\mathbf{2 6})$ \\
\hline
\end{tabular}

The results of English-isiXhosa for the same three tasks discussed are given in Table 4. The PS1, PS2, and PS3 item elicited 40\%, 48\% and 50\% ORs respectively, and an average percentage of $46 \%$ in the isiXhosa test. In fact, there was an increase of $15 \%$ ORs in the isiXhosa test after already having seen the English. This finding indicates that learners' responses on the three tasks in the isiXhosa items were mathematically correct after seeing the same tasks in the English test. Only 8\% of the learners produced realistic answers on the three tasks of the English test, compared to an increase of $4 \%$ generated for the isiXhosa test. The increase in percentage of the RRs revealed that not only more computationally correct responses were generated in the isiXhosa test, but there was also a slight improvement in the percentage of learners who succeeded in producing situationally appropriate answers. 
Table 4. Percentages (and absolute numbers) of realistic reactions (RRs), other reactions (ORs), and no reactions (NRs) on the three problem-solving (PS) English items for the English-isiXhosa (EI) Experimental group

\begin{tabular}{ccccccccc}
\hline Item & PS1 & PS2 & PS3 & Total & PS1 & PS2 & PS3 & Total \\
\hline & \multicolumn{2}{c}{ English Items } & & \multicolumn{4}{c}{ isiXhosa ltems } \\
\cline { 2 - 9 } RR & $19 \%$ & $2 \%$ & $2 \%$ & $\mathbf{8} \%$ & $8 \%$ & $21 \%$ & $6 \%$ & $\mathbf{1 2 \%}$ \\
& $(10)$ & $(1)$ & $(1)$ & $(12)$ & $(4)$ & $(11)$ & $(3)$ & $(18)$ \\
OR & $37 \%$ & $35 \%$ & $21 \%$ & $31 \%$ & $40 \%$ & $48 \%$ & $50 \%$ & $46 \%$ \\
& $(19)$ & $(18)$ & $(11)$ & $(58)$ & $(21)$ & $(25)$ & $(26)$ & $(72)$ \\
NR & $44 \%$ & $63 \%$ & $77 \%$ & $61 \%$ & $52 \%$ & $31 \%$ & $44 \%$ & $\mathbf{4 2} \%$ \\
& $(23)$ & $(33)$ & $(40)$ & $(96)$ & $(27)$ & $(16)$ & $(23)$ & $(66)$ \\
\hline
\end{tabular}

\section{Qualitative Results}

The learners' interviews were conducted to investigate which language they prefer to use during classroom interaction, to communicate, when they solve mathematical problems, and for assessment, and why? The results are presented below using a few selected extracts as examples from learners' responses. All questions were in English and asked in the same order for all the four experimental groups, consisting at most eight learners per group. Learners were free to respond in their home languages, but all the learners chose to respond in English.

On average most of the learners indicated, from their responses, that English was a preferred language for classroom communication, when they individually talk to the teacher and present their group work to the entire classroom. This explanation was given in response to the question regarding the language that they use for communication in the classroom. Extract 1 represents texts from the two groups of learners in different schools.

\section{Extract 1}
L(earners): English
R(esearcher): Why English?
L1:
Because when you are educated you must know how to speak English, because maybe you will be hired in a job by a white person not Xhosa speaking person and you will be required to speak English.
R: OK
L2: $\quad$ You must use English because when you write in mathematics book you will not write isiXhosa because it is not a Xhosa period or Xhosa class, you also provide written answers in English, so it's better for you to answer in English, and become used in speaking and answering in English.
L3: $\quad$ And English is the most used language here in South Africa.
R: $\quad$ Any other reason?
L5: $\quad$ English helps you to communicate with people from other countries, for an example the visitors for 2010 soccer world cup, we will be able to communicate with them in English because they will not understand isiXhosa.

Of many things which the texts in Extract 1 may suggest, what comes to the forefront is the learners' reasons for the use and association of "English" with "hired in a job", "the most used language here in South Africa" and "communicate with people from other countries". All these learners, in exception of learner 2, provide reasons that are not necessarily related to their classroom interactions, but those that affect their everyday-life challenges. In other words, issues that emerge are connected to a notion of using English for social class purposes, including those linked to social goods. The frequent use of the word "must" emphasises the feeling of obligation that the learners expresses in using this language to "write in mathematics book" in order to "provide written answers in English", as stated in Extract 1 by learner 2. These pronouncements appear to suggest that learners do not have a say or a choice regarding the language used in the teaching and learning of mathematics.

Learners were also asked about the language(s) that they prefer to use when solving word problems, and why. The aim of this question was to understand mathematical discourses that occur when learners solve problems in groups and/or pairs. Data gathered from their responses to this question revealed that learners used isiXhosa to solve word problems in their groups. They primarily used their home language and then translated their solution statements into verbal and written English when they presented their solutions to the entire classroom, and in their notebooks respectively. For example, one of the learners stated that "We discuss in isiXhosa, but in the answer book we write English and we give presentation to the teacher in English". Although some of the few groups employed a parallel use of 
English and isiXhosa, the strategy of translating from learners' home language was consistently applied across all the experimental classrooms, with learners switching or moving from their home language to English.

\section{Discussion of Results}

This section provides a discussion of findings within a framework of a literature reviwed and theories used in the study discussed in this article according to the following categories:

\subsection{Language use and word problem-solving}

The results of the study echo a finding by Ellerton and Clements (1991) that a major source of difficulty with mathematical word problems can be attributed to the fact that the language of mathematics and the language of common English usage often differ in important ways. Although experimental teachers have often assumed that poor performances in word problems have arisen from lack of understanding of mathematical concepts or a deficiency in computing skills (Hater, Kane, \& Byrne, 1974), the errors have been caused by an inadequate understanding of the language of mathematics. In fact, the test results indicate that the solution errors on the problem-solving (PS) tasks seem to reflect deficiencies in logico-mathematical knowledge (De Corte, Verschaffel, \& De Win, 1985), not akin to Cummins et al.'s (1988) reasoning fallacies.

\subsection{Test order: English-isiXhosa (EI) and isiXhosa-English (IE) groups}

The English-isiXhosa (EI) group produced more mathematically correct answers in their home language, after responding to word problems in English first. The improvement in problem-solving abilities of the El group in the isiXhosa test may possibly be attributed to the fact that English, as LoLT, as a commonly used formal written mathematical language empowered learners with clearer understanding of problems in their home language, and as such, there was a successful move from formal written language to informal spoken mathematical language. However, answering the isiXhosa test first resulted in the isiXhosa-English (IE) group showing a tendency to relegate reality or common-sense when solving word problems in English. This finding suggests that a decline in learners' problem-solving appeared to stem from their inability to comprehend word problems in isiXhosa test. In other words, it appeared that having seen the test in English first made it easier for the experimental learners to comprehend and make sense of the word problems in the isiXhosa test. This finding may have implications for teacher practice in multilingual mathematics classrooms of the Eastern Cape Province.

\subsection{Reality, sense-making, and context in word problem-solving}

A report by Julie and Mbekwa (2005) raises concerns with the way in which the notion of what constitutes a 'relevant context' might not be in the same for curriculum developers, teachers, and learners. In other words, the overall results of the study suggest that mathematics word problems used in school curricula are not relevant to and do not address the socio-cultural situations faced by and known to the learners from poor socio-economic backgrounds. Sethole (2004) suggests that foregrounding of context may lead to a loss of focus on the development of conceptual mathematics knowledge and render the mathematics invisible or inaccessible. Contrary to this, the results of this study suggest that with well-planned and effective teacher development interventions, the issue of context in mathematics teaching may play a pivotal role in the development of learners' problem-solving abilities. The test results indicated that current school instruction given for mathematical word problems is likely to develop in students a tendency to exclude real-world knowledge and/or reality in their solution processes (Cooper \& Harries, 2005; Greer, 1997; Verschaffel, De Corte, Lasure, Vaerenbergh, Bogaerts, \& Ratinckx, 1999).

According to a socio-cultural perspective, modelling implies engaging in inter-semiotic work, that is, one has to decide about the appropriate and productive manners of coordinating linguistic categories and mathematical expressions and operations in order to come to a solution of a problem (Säljö, Riesbeck, \& Wyndham, 2009). Learners' tests responses indicate that strategies employed by the experimental group teachers, when teaching word problems, put more emphasis on syntax and mathematics rules rather than, what Xin (2009) refers to as, a description of some realworld situation to be modelled mathematically. As a result, it could be argued that a significant number of learners who produced the no reactions (NRs) for PS tasks might have made realistic considerations during the solution process of the PS tasks, but finally have decided to neglect these realistic considerations in their final answers. Learners may have simply anticipated that such 'unusual answers' would not be appreciated by the researcher and/or the mathematics 
teacher (Verschaffel et al., 2000). However, analysis of the effects of promoting discussion and use of out-of-school mathematics revealed that the ability to take into account real-world considerations properly when solving word problems increased, as expected, with sense making.

\section{Conclusion}

The overall results of this study reported in this article appeared to suggest that learners' performance on word problems differed dramatically depending on how the problems are structured and presented to the problem-solvers. Moreover, the types of word problems used in the study reported here seemed to require consideration of how the situation (or context) should be modelled, and if the information provided is relevant to the problem-solver and adequate for the learners to solve the problem. The policy designers are encouraged to view the official language of learning and teaching in South African public schools as an additional resource and not merely a policy that should be implemented. This may allow the school to encourage learners and teachers to use appropriate language in good timing for various groups of learners in a way that will support and improve academic achievement in word problem solving. The findings seemed to suggest that learners appeared to be successful problem-solvers in cases where the dual-use of LoLT and learners' home language was evident.

\section{References}

Bjork, R. A. (1994). Memory and metamemory considerations in the training of human beings. In J. Metcalfe and A. Shimamura (Eds.), Metacognition: Knowing about knowing (pp.185-205). Cambridge, MA: MIT Press.

Alidou, H., \& Brock-Utne, B. (2005). Teaching practices - Teaching in a familiar language. Namibia: GTZ report, 102-126.

Baldauf, R., \& Kaplan, R. (2005). Language-in-Education Policy and planning. In E. Hinkel (Ed.), Handbook of research in second language teaching and learning. Mahwah, NJ: Erlbaum.

Chitera, N. (2009). Discourse practices of mathematics teacher educators in initial teacher training colleges in Malawi. Johannesburg, South Africa: Unpublished PhD Thesis, University of Witwatersrand.

Cobb, P., Wood, T., \& Yackel, E. (1993). Discourse, mathematical thinking, and classroom practice. In E. Forman, N. Minick, \& C. Stone (Eds.), Contexts for learning: Sociocultural dynamics in children's development (pp. 91-119 ). Oxford, UK: Oxford University Press.

Cooper \& Harries. (2005). Making sense of realistic word problems: Portraying working class "failure" in a division with a remainder problem. International Journal of Research \& Methods in Education, 22, 449-463.

Cummins, D. D., Kintsch, W., Reusser, K., \& Weimer, R. (1988). The role of understanding in solving word problem. Cognitive Psychology, 20, 405-438.

De Corte, E., Verschaffel, L., \& DeWin, L. (1985). The influence of rewording verbal problems on children's problem representation and solutions. Journal of Educational Psychology, 11, 460-470.

De La Paz, S., \& Graham, S. (1997). Strategy instruction in planning: effects on the writing performance and behaviour of students with learning difficulties. Exceptional Children, 63, 167-181.

Department of Education. (2012). National Curriculum Statements Grades 10 - 12 (General). Pretoria: Government Printers

Ellerton, N. F., \& Clements, M. A. (1991). Mathematics in language: A review of language factors in mathematics learning. Geelong, Australia: Deakin University.

English, L. (1998). Children's problem posing within formal and informal contexts. Journal for Research in Mathematics, 29, 83-106.

Fleisch, B. (2008). Primary education in crisis: Why South African children underachieve in reading and mathematics. Cape Town: Juta.

Greer, B. (1997). Modelling reality in mathematics classrooms: The case of word problems. Learning and Instruction, 7, $293-307$.

Güles, N. (2005). The struggle for English. Johannesburg, South Africa: The Sunday Times (9 January 2005).

Gutiérrez, R. (2002). Enabling the Practice of Mathematics Teachers in Context: Toward A new Equity Research Agenda. In Mathematical Thinking and Learning, 4(2 \& 3), $145-187$.

Howie, S. J. (2004). A national assessment in mathematics within international comparative assessment. Perspectives in Education, 22, 149-162.

Howie, S. J. (2003). Language and other backgrouynd factors affecting secondary pupils' performance in Mathematics in South Africa. African Journal of Research in Science, Mathematics and Technology Education, 7, 1-20.

Jonassen, D. (2004). Learning to solve problems: An instructional design guide. San Francisco, CA: Pfeiffer.

Julie, C., \& Mbekwa, M. (2005). What would grade 8 to 10 learners prefer as context for mathematical literacy? The case of Masilakele Secondary School. Perspective in Education, 23(3), 31- 43.

Kilpatrick, J. (1987). Problem formulating: Where do good problems come from? In A. Schoenfeld (Ed.), Cognitive science and mathematics education (pp. 123-147). Hillsade, NJ: Erlbaum.

Lerman, S. (2001 ). Cultural, Discursive Psychology: A sociocultural approach to studyng the teaching and learning of mathematics. Educational Studies in Mathematics, 46, 87-113.

Loranger, A. (1997). Comprehension Strategies instruction: Does it make a difference? Reading Psychology, 18(1), 31-68. 
Padron, Y. (1985). Utilizing cognitive reading strategies to improve English Reading comprehension of Spanish-Speaking bilingual students. University of Houston: Unpublished doctoral dissertation.

Phillips, J. (1984). Practical Implications of recent research in reading. Foreign Language Annals, 17(4), 285-296.

Säljö, R., Riesbeck, E., \& Wyndham, J. (2009). Learning to model: Coordinating natural language and mathematical operations when solving word problems. In L. Verschaffel, B. Greer, W. Van Dooren, \& S. Mukhopadhyay (Eds.), Words and Worlds: Modelling verbal desc (pp. 177-193). Netherlands: Sense Publishers.

Sepeng, P. (2013). Exploring Mathematics Classroom Practices in South African Multilingual Settings. Mediterranean Journal of Social Sciences, 4(6), 627-638.

Sepeng, P., \& Webb, P. (2012). Exploring mathematical discussion in word problem-solving. Pythagoras, 33(1), 1-8.

Setati, M. (2005a). Power and access in multilingual mathematics classrooms. Proceedings of the 4th international mathematics education and society conference. Australia: Centre for learning and research, Griffith University.

Setati, M. (2005b). Teaching mathematics in a primary multilingual classroom. Research in mathematics education, 36(5), 447-466.

Setati, M., Molefe, T., \& Langa, M. (2008). Using Language as a Transparent Resource in the Teaching and Learning of Mathematics in a Grade 11 Multilingual Classroom. Pythagoras: Journal of the Association for Mathematics Education of South Africa, 67, 14-25.

Sethole, G. (2004). Meaningful context or dead mock reality: which form will the everyday take? Pythagoras, 59, 18-25.

Taylor, N., \& Vinjevold, P. (1999). Getting Learning Right: Report of the President's Education Initiative Research Project. Johannesburg, South Africa: Joint Education Trust.

Verschaffel, L., De Corte, E., Lasure, S., Vaerenbergh, G.V., Bogaerts, H., \& Ratinckx, E. (1999). 'Learning to solve mathematical application problems: A design experiment with fifth graders'. Mathematical Thinking and Learning, 1(3), 195-229.

Verschaffel, L., De Corte, E., \& Lasure, S. (1994). Realistic considerations in mathematical modelling of school arithmetic word problems. Learning and Instruction, 4, 273-294.

Verschaffel, L., Greer, B., \& De Corte, E. (2000). Making sense of word problems. The Netherlands: Swets \& Zeitlinger.

Verschaffel, L., Van Dooren, W., Chen, L., \& Stessen, K. (2009). The relationship between posing and solving division-with-remainder problems among Flemish upper elementary school children. In L. Verschaffel, B. Greer, W. Van Dooren, \& S. Mukhopadhyay (Eds.), Words and Worlds: Modelling Verbal Descriptions of Situations (pp. 143-160). Rotterdam: Sense Publishers.

Vygotsky, L. (1978). Mind in Society: The Development of Higher Psychological Processes. Cambridge, MA: Harvard University Press.

Xin, Z. (2009). Realistic problem solving in china: Students' performances, interventions, and learning settings. In L. Verschaffel, B. Greer, W. Van Dooren, \& S. Mukhopadhyay (Eds.), Words and Worlds: Modelling verbal descriptions of situations (pp. 161-176). Netherlands: Sense Publishers.

Xin, Z., Lin, C., Zhang, L., \& Yan, R. (2007). The performance of Chinese primary school students on realistic arithmetic word problems. Educational Psychology in Practice, 23, 145-159. 